\title{
Determinants of uncontrolled hypertension in adult type 2 diabetes mellitus: an analysis of the Malaysian diabetes registry 2009
}

Boon How Chew ${ }^{1 *}$, Ismail Mastura ${ }^{2}$, Sazlina Shariff-Ghazali ${ }^{1}$, Ping Yein Lee ${ }^{1}$, Ai Theng Cheong ${ }^{1}$, Zaiton Ahmad ${ }^{1}$, Sri Wahyu Taher ${ }^{3}$, Jamaiyah Haniff ${ }^{4}$, Feisul Idzwan Mustapha ${ }^{5}$ and Mohd Adam Bujang ${ }^{4}$

\begin{abstract}
Background: Uncontrolled blood pressure (BP) is a significant contributor of morbidity and even mortality in type 2 diabetes (T2D) patients. This study was done to determine the significant determinants of uncontrolled blood pressure in T2D patients in Malaysia.

Methods: Between $1^{\text {st }}$ January 2009 to $31^{\text {st }}$ December 2009, data from 70889 patients with Type 2 diabetes was obtained from the Adult Diabetes Control and Management Registry for analysis; 303 centers participated in the study. Their demographic characteristics, the nature of their diabetes, their state of hypertension, treatment modalities, risk factors, and complications are described. Based on their most recent BP values, subjects were divided into controlled BP and uncontrolled BP and their clinical determinants compared. Independent determinants were identified using multivariate logistic regression.

Results: The mean age of patients at diagnosis of diabetes was $52.3 \pm 11.1$ years old. Most were women (59.0\%) and of Malay ethnicity (61.9\%). The mean duration of diabetes was $5.9 \pm 5.6$ years. A total of $57.4 \%$ were hypertensive. Of the 56503 blood pressure (BP) measured, 13280 (23.5\%) patients had BP <130/80 mmHg. Eighteen percent was on $>$ two anti-hypertensive agents. Health clinics without doctor, older age ( $\geq 50$ years old), shorter duration of diabetes ( $<5$ years), Malay, overweight were determinants for uncontrolled blood pressure (BP $\geq 130 / 80 \mathrm{mmHg}$ ). Patients who were on anti-hypertensive agent/s were 2.7 times more likely to have BP $\geq 130 /$ $80 \mathrm{mmHg}$. Type 2 diabetes patients who had ischaemic heart disease or nephropathy were about $20 \%$ and $15 \%$ more likely to have their blood pressure treated to target respectively.

Conclusions: Major independent determinants of uncontrolled BP in our group of T2D patients were Malay ethnicity, older age, recent diagnosis of diabetes, overweight and follow-up at health clinics without a doctor and possibly the improper use of anti hypertensive agent. More effort, education and resources, especially in the primary health care centres are needed to improve hypertensive care among our patients with diabetes.
\end{abstract}

Keywords: Type 2 Diabetes Mellitus, Hypertension, Antihypertensive agents, Primary care

\footnotetext{
* Correspondence: chewboonhow@yahoo.com

${ }^{1}$ Department of Family Medicine, Faculty of Medicine \& Health Sciences,

Universiti Putra Malaysia, 43400 Serdang, Selangor, Malaysia

Full list of author information is available at the end of the article
} 


\section{Background}

The profile of blood pressure (BP) management in Type 2 diabetes mellitus (T2D) patients has generally been unsatisfactory until about two decades ago [1,2]. In 1987, the Hypertension in Diabetes Study (HDS) revealed that most of the hypertensives went unrecognized, untreated and if treated, the target blood pressure (BP) was unacceptably high when compared to the current criteria [3]. The study also revealed the benefits of lowering blood pressure in these patients. It showed that the reduction of a mean blood pressure of between 5 to $10 \mathrm{mmHg}$, reduced the diabetes related deaths by one-third, the incidence of stroke by almost half and reduced the incidence of heart failure by almost one-third after a median follow-up period of 8.4 years. Furthermore, detailed analysis showed that the number needed to treat (NNT) to prevent one major complication of diabetes was 6 patients and 15 patients for death [3]. These benefits also appeared more favourable than those resulting from the intensified glycaemic control strategy for microvascular endpoints (NNT 138 vs 357). Many other studies had showed similar detrimental consequences of poor control of hypertension in diabetics. A systematic review of observational studies involving close to 48000 patients showed that uncontrolled hypertension had a significant impact on diabetesrelated complications [4]. Also, of importance was Framingham study which showed that while the risk of death $(7 \%)$ and cardiovascular events (9\%) could be attributed to diabetes, the risk of death and cardiovascular events attributed to co-existent hypertension were far higher; $44 \%$ and $41 \%$ respectively [5].

Patients with diabetes are especially vulnerable to hypertensive injury. The coexistence of hypertension has a significant impact of the poor prognosis for patients with diabetes because of its effect on the micro and macro vasculature. These include impaired autoregulation of blood flow in the microcirculation, the non-dipping of nocturnal BP owing to autonomic dysfunction, increased pulse-wave velocity and ventricularvascular mis-coupling from premature stiffening of the abdominal aorta by elastic fibres glycation [6-9]. The additional advantages of intensive and good BP control for T2D patients are the increase of quality-adjusted life-years (QALYs) and cost-effectiveness. This benefit resulted from reduced cost of managing complications, increased survival and an increase in the interval-free complications [10,11]. Furthermore, the cost of managing a T2D patient is not cheap. In Malaysia even in the Public Health Service, the cost averaged around US 350 dollars a month if the patient saw a family physician or US 250 dollars if he or she saw a non-specialist. If the patient was admitted for treatment the cost doubled and , if for complications e.g. stroke, foot gangrene, the cost would escalate 10-fold [12].
Clearly there is convincing evidence on the benefits of effectively treating T2D patients who have hypertension. However, we have no national data on this aspect of the problem and neither do we know how effective we have been in dealing with the problem. We therefore set out to assess the care these patients have been given and in particular, the variables that had a significant impact on the uncontrolled blood pressure. We hoped that the results will shed some light on the problem and guide policy-makers in developing appropriate strategies for prevention and for the proper allocation of health resources to this area of diabetic management.

\section{Methods}

This was a cross-sectional study using data extracted from the Adult Diabetes Control and Management (ADCM) Registry in 2009. It represents 70889 T2D patients from 289 health clinics and 14 hospitals and from 8 of the 15 states in the country and 2 Federal territories. These represent $22.1 \%$ of the health clinics and $9.6 \%$ of the hospitals in the country. It has been estimated that these patients represent $5.2 \%$ of the total number of diabetics in these areas (70889/1368590) [13]. Up to $31^{\text {st }}$ December 2009, 3140 (4.4\%) were lost to follow-up (defaulted appointment for $>$ one year) and 203 (0.3\%) patients had passed on.

Only adult patients ( $\geq 18$ years of age) were registered. All patients were informed of the on-going registry and given the opportunity to opt out. However, the participation in ADCM was non-mandatory for patients and health centres. Data collection at local centers was performed by trained physicians, assistant physicians and nurses. All data on the participating patients were registered on an on-line standard case record form (CRF) and the information was made available in the ADCM website. This website was maintained by Clinical Research Centre (CRC), Ministry of Health, Malaysia.

\section{The Malaysian health care system for patients with diabetes}

The health care system in Malaysia is supported by the public and the private sectors [14]. The private health care provides about two thirds of the country's medical specialists and caters for about one third of the uppermiddle income groups of the population [15]. The public health care is organized by Ministry of Health and structured into the public health clinics and hospital care. The health clinics are well-linked to the secondary and tertiary public hospitals with its unique referral system. The patients in health clinics generally are managed by family medicine specialists (FMS), medical and health officer $(\mathrm{M} \& \mathrm{HO})$, physician assistant and supported by specialized nurses and dietitians/nutritionists. In hospitals, care is provided by specialists in internal medicine 
or endocrinology, medical officers and specialized nurses. Under the system, every patient diagnosed with diabetes mellitus will receive a green booklet which will be kept by the patient. This is accompanied with a bigger green medical record book (kept at the health centre) that records all information pertaining to the care provided for the patient's management. Those patients managed in the health clinics and who have complications are referred to the hospitals either for admission or for a co-shared care as outpatients. In health clinic without a FMS/M\&HO, the cases are normally managed by physician assistants. Nurses at these health clinics contributed in measuring clinical parameters during patients' visit and giving health education at the appointment day. Another reason for this referral is for the prescription of more expensive anti-diabetic agents (ADA), lipid-lowering agents or the newer or more expensive anti-hypertensive drugs. These are restricted items and can only be dispensed at the hospitals [16]. All major classes of anti-hypertensive drugs (including renin inhibitors, angiotensin receptor blockers, calcium channel blockers) are available in the public health sector. The newer, original and more expensive drugs are restricted and those that of older and generic are commonly used in patient care in compliance to the national clinical practice guideline.

\section{Definitions of study participants}

A person was considered to have T2D if there was documented evidence of a diagnosis of diabetes mellitus (WHO criteria) and who was being treated either by lifestyle modification, oral ADA or insulin. Hypertension was diagnosed if the systolic blood pressure was $\geq 130 \mathrm{~mm} \mathrm{Hg}$ or the diastolic blood pressure was $\geq 80 \mathrm{~mm} \mathrm{Hg}$ on each of two successive readings measured in rested position with arm at heart level using a cuff of appropriate size; a $\mathrm{BP}<130 / 80 \mathrm{mmHg}$ was regarded as well controlled. Body mass index (BMI) was calculated as weight (kilogram) divided by height (metre) squared and categorized into underweight $(<18.5)$, normal $(18.5-22.9)$ and overweight $(\geq 23.0)$; for the category of obesity it was further classified into pre-obese (23.0-27.4), obese I (27.5-34.9), obese II (35.0-39.9) and obese III ( $\geq 40)$. For their lipid profiles, a low density lipoprotein-cholesterol (LDL-C) $\leq 2.6 \mathrm{mmol} / \mathrm{L}$, triglyceride $(\mathrm{TG}) \leq 1.7 \mathrm{mmol} / \mathrm{L}$ and high density lipoprotein-cholesterol $\quad(\mathrm{HDL}-\mathrm{C}) \geq 1.1 \quad \mathrm{mmol} / \mathrm{L}$ were regarded as good treatment targets [17].

A diagnosis of cerebrovascular disease/stroke (CVD), ischemic heart disease (IHD), retinopathy, nephropathy and foot problem were based on symptoms, signs, laboratory results, radiological evidence and treatment history. Nephropathy was diagnosed by the presence on $\geq 2$ occasions and at least three months apart of any of the following: microalbuminuria, proteinuria, serum creatinine $>150 \mathrm{mmol} / \mathrm{L}$ or estimated glomerular filtration rate $<60 \mathrm{mls} / \mathrm{min}$ (Cockroft-Gault formula). Foot problems were defined as any deformity resulted from ulcers, amputation, peripheral neuropathy or peripheral vascular disease.

\section{Statistical analysis}

The independent variables of interest were the types of clinic and how it was manned, gender, ethnicity, age, duration of diabetes, body mass index (BMI), waist circumference, CVD, IHD, retinopathy, nephropathy, erectile dysfunction (ED), diabetic foot problems, antihypertensive treatment, glycaemic control $[\mathrm{HbA} 1 \mathrm{c} \leq 6.5 \%$ (48 $\mathrm{mmol} / \mathrm{mol}$ )] and lipid profile control (LDL$\mathrm{C} \leq 2.6 \mathrm{mmol} / \mathrm{L}, \mathrm{TG} \leq 1.7 \mathrm{mmol} / \mathrm{L}, \mathrm{HDL}-\mathrm{C} \geq 1.1 \mathrm{mmol} / \mathrm{L}$ ).

Mean levels were compared using the Student's t test for unpaired samples and proportions compared with Chi square test. The normality of each variable was first tested by histogram and confirmed by KolmogorovSmirnov test. A two-tailed $\mathrm{P}$ value of $<0.05$ was considered to be significant.

Having grouped the patients into controlled and uncontrolled BP using the latest mean BP values, logistic regression was used to determine the significant clinical determinants. The significant determinants were then identified and fitted into a multivariate logistic regression model using the stepwise method with uncontrolled $\mathrm{BP}$ as the dependent variable. Multicolinearity between the variables were checked with correlation matrix and inspected for the magnitude of the standard error (SE). None of the variables correlated with each other, $r<0.2$ and SEs were all within 0.001 to 5.0. All data was analysed using STATA version 9.

\section{Results}

Of the 70889 patients with T2D analysed, most were women (59.0 \%) and Malays $62 \%$ ) (Table 1$)$. The mean age at diagnosis of diabetes was $52.3 \pm 11.1$ years and the mean duration of diabetes was $5.9 \pm 5.6$ years. The mean systolic and diastolic blood pressures (BP) were $136.7 \pm 19.5 \mathrm{mmHg}(95 \% \mathrm{CI}, 136.6$ to 136.9$)$ and $78.8 \pm 10.6 \mathrm{mmHg}(95 \% \mathrm{CI}, 78.7$ to 78.9$)$ respectively. A total of $40659(57.4 \%)$ patients were reported to be hypertensive. Of the $56503 \mathrm{BP}$ measurements recorded from these patients, $33.8 \%$ had systolic $\mathrm{BP}<130 \mathrm{mmHg}$, $44.8 \%$ had diastolic $\mathrm{BP}<80 \mathrm{mmHg}$ and $23.5 \%$ patients had $\mathrm{BP}<130 / 80 \mathrm{mmHg}$. A more detailed report on this has been published elsewhere [13].

The variables that determined good control of BP on univariate analysis were, the type of health clinic, ethnicity, age group, duration of diabetes, BMI, HbA1c, targets of lipid profiles and use of anti-hypertensive agent (Table 1; Figure 1) Although insulin use was associated with blood pressures being controlled to target 
Table 1 Association of registered variables with blood pressure controlled to target, $\mathbf{n}=56503^{*}$

\begin{tabular}{|c|c|c|c|c|}
\hline Variable & Total $\mathrm{n}$ (\% of total) & Controlled BP n (\%) & Uncontrolled BP n (\%) & Test statistic value, $p$-value \\
\hline Total & $56503(100)$ & $13280(23.5)$ & $43223(76.5)$ & NA \\
\hline \multicolumn{5}{|l|}{ Type of Health Clinic, n= 53941} \\
\hline Without FMS/doctor & $12009(22.3)$ & $2558(21.3)$ & $9451(78.7)$ & \multirow[t]{2}{*}{$48.81,<0.001^{*}$} \\
\hline With FMS/doctor & $41932(77.7)$ & $10221(24.4)$ & $31711(75.6)$ & \\
\hline \multicolumn{4}{|l|}{ Gender } & \multirow[t]{4}{*}{$2.66,0.27^{*}$} \\
\hline Male & $22548(39.9)$ & $5326(23.6)$ & $17222(76.4)$ & \\
\hline Female & $33866(59.9)$ & $7927(23.4)$ & $25939(76.6)$ & \\
\hline Missing & $89(0.2)$ & $27(30.3)$ & $62(69.7)$ & \\
\hline \multicolumn{4}{|l|}{ Ethnicity } & \multirow[t]{6}{*}{$344.98,<0.001^{*}$} \\
\hline Malay & $35181(62.3)$ & $7484(21.3)$ & $27697(78.7)$ & \\
\hline Chinese & $11051(19.6)$ & $2761(25.0)$ & $8290(75.0)$ & \\
\hline Indian & $9627(17.0)$ & $2891(30.0)$ & $6736(70.0)$ & \\
\hline Others & $558(1.0)$ & $119(21.3)$ & $439(78.7)$ & \\
\hline Missing & $86(0.2)$ & $25(29.1)$ & $61(70.9)$ & \\
\hline \multicolumn{5}{|l|}{ Age group (year) } \\
\hline Mean (SD) & $(58.32,11.27)$ & $(57.21,11.43)$ & $(58.38,10.86)$ & $10.717,<0.001^{\#}$ \\
\hline$<30$ & $445(0.8)$ & $147(33.0)$ & $298(67.0)$ & \multirow[t]{4}{*}{$143.83,<0.001^{*}$} \\
\hline $30-49$ & $11452(20.3)$ & $3128(27.3)$ & $8324(72.7)$ & \\
\hline $50-69$ & $35877(63.5)$ & $8029(22.4)$ & $27848(77.6)$ & \\
\hline$>=70$ & $8729(15.4)$ & $1976(22.6)$ & $6753(77.4)$ & \\
\hline \multicolumn{5}{|l|}{ Duration of diabetes (year) } \\
\hline Mean (SD) & $(5.86,5.56)$ & $(5.99,5.59)$ & $(5.75,5.47)$ & $4.457,<0.001^{\#}$ \\
\hline$<5$ & $28704(50.8)$ & $6555(22.8)$ & $22149(77.2)$ & \multirow[t]{4}{*}{$17.29,0.001^{*}$} \\
\hline $5-10$ & $19528(34.6)$ & $4677(23.9)$ & $14851(76.1)$ & \\
\hline$>10$ & $7962(14.1)$ & $1979(24.8)$ & $5983(75.2)$ & \\
\hline Missing & $309(0.5)$ & $69(22.3)$ & $240(77.7)$ & \\
\hline BMI (kg/m2) & $53687(100)$ & $12677(23.6)$ & $41010(76.4)$ & \\
\hline Mean (SD) & $(27.28,5.96)$ & $(26.46,5.16)$ & $(27.53,6.16)$ & $17.72,<0.001^{\#}$ \\
\hline Underweight < 18.5 & $890(1.7)$ & 317 (35.6) & $573(64.4)$ & \multirow[t]{3}{*}{$250.44,<0.001^{*}$} \\
\hline Normal 18.5-22.9 & $8792(16.4)$ & 2544 (28.9) & $6248(71.1)$ & \\
\hline Overweight $\geq 23.0$ & $44005(77.9)$ & $9816(22.3)$ & $34189(77.7)$ & \\
\hline Pre-obese 23.0-27.4 & $20868(38.9)$ & $5118(24.5)$ & $15750(75.5)$ & \multirow[t]{4}{*}{$148.07,<0.001^{*}$} \\
\hline Obese I 27.5-34.9 & $19343(36.0)$ & $4065(21.0)$ & $15278(79.0)$ & \\
\hline Obese II 35.0-39.9 & $2815(5.2)$ & $478(17.0)$ & $2337(83.0)$ & \\
\hline Obese III $\geq 40$ & $979(1.8)$ & $155(15.8)$ & $824(84.2)$ & \\
\hline $\mathrm{HbA1c} \leq 6.5 \%(48 \mathrm{mmol} / \mathrm{mol})$ & $26052(46.1)$ & $6228(23.9)$ & $19824(76.1)$ & \multirow[t]{2}{*}{0.04} \\
\hline > $6.5 \%$ (48 mmol/mol) & $30451(53.9)$ & $7052(23.2)$ & $23399(76.8)$ & \\
\hline LDL-C $\leq 2.6 \mathrm{mmol} / \mathrm{L}$ & $11990(21.2)$ & $3016(25.2)$ & $8974(74.8)$ & \multirow[t]{2}{*}{$<0.001$} \\
\hline$>2.6 \mathrm{mmol} / \mathrm{L}$ & $44513(78.8)$ & $10264(23.1)$ & $34249(76.9)$ & \\
\hline \multicolumn{4}{|l|}{$\mathrm{TG}, \mathrm{n}=44121$} & \multirow[t]{3}{*}{$<0.001$} \\
\hline$\leq 1.7 \mathrm{mmol} / \mathrm{L}$ & $23867(54.1)$ & $6018(25.2)$ & $17849(74.8)$ & \\
\hline$>1.7 \mathrm{mmol} / \mathrm{L}$ & $20254(45.9)$ & $4412(21.8)$ & $15842(78.2)$ & \\
\hline HDL-C $\geq 1.1 \mathrm{mmol} / \mathrm{L}$ & $43986(77.8)$ & $10235(23.3)$ & $33751(76.7)$ & \multirow[t]{2}{*}{0.01} \\
\hline$>1.1 \mathrm{mmol} / \mathrm{L}$ & $12517(22.2)$ & $3045(24.3)$ & $9472(75.7)$ & \\
\hline
\end{tabular}

$\mathrm{A} B \mathrm{BP}<130 / 80 \mathrm{mmHg}$ was regarded as controlled $\mathrm{BP}$.

$\mathrm{NA}=$ not applicable.

Missing rows represent either missing value of the variable or BP measurement, ${ }^{\ddagger}$ the total used as the denominator in the total column, the different total is otherwise stated in the sub-headings, ${ }^{*}$ Chi-square test on category variables, and " $t$-test on continues variables (not including missing). 
$\left(x^{2}=19.14, p<0.001\right)$, this association was not seen for $\mathrm{ADA}$, diet therapy and HbA1c levels.

Of interest was that those who were being treated for hypertension did not have their blood pressure control on target (Figure 1) This was irrespective of whether they were on single $\left(80.1 \%\right.$ vs $74.7 \%, x^{2}=204.66$, $\mathrm{p}<0.001)$, double $\left(82.6 \%\right.$ vs $74.6 \%, \mathrm{x}^{2}=371.69$, $\mathrm{p}<0.001)$ or $\geq$ triple anti-hypertensive agents $(82.7 \%$ vs $\left.75.5 \%, X^{2}=186.98, \mathrm{p}<0.001\right)$.

Of the $41286(58.2 \%)$ patients on anti-hypertensive agents, angiotensin-converting enzyme inhibitors (ACEI) $(63.9 \%)$ were the most prescribed, followed by calcium channel blockers (CCB) (37 \%) beta-blockers $(36.5 \%)$ and diuretics $(23.4 \%)$. The use of specific anti-hypertensive drug classes had been assessed and reported elsewhere [13].

Health clinics without a doctor, older age $(\geq 50$ years old), shorter duration of diabetes ( $<5$ years), non-Indians (being Malay), overweight, being on anti-hypertensive agents and having poor lipid profile (LDL-C $>2.6$ $\mathrm{mmom} / \mathrm{L}$ ) were predictors for uncontrolled blood pressure ( $\mathrm{BP} \geq 130 / 80 \mathrm{mmHg}$ ). Patients who were on antihypertensive agent/s were 2.7 times more likely to have uncontrolled BP. T2D patients who had IHD or nephropathy were about $20 \%$ and $15 \%$ more likely to have their blood pressure treated to target, respectively (Table 2).

\section{Discussion}

We set out to examine the status of our T2D patients with hypertension. The results were sub-optimal; less than one in four patients had their BPs controlled to the recommended target. This is despite convincing evidence that aggressive lowering of BP in people with diabetes reduces cardiovascular morbidity and mortality [18] Furthermore, the poor control persisted despite the fact that they were being treated and in some, with more

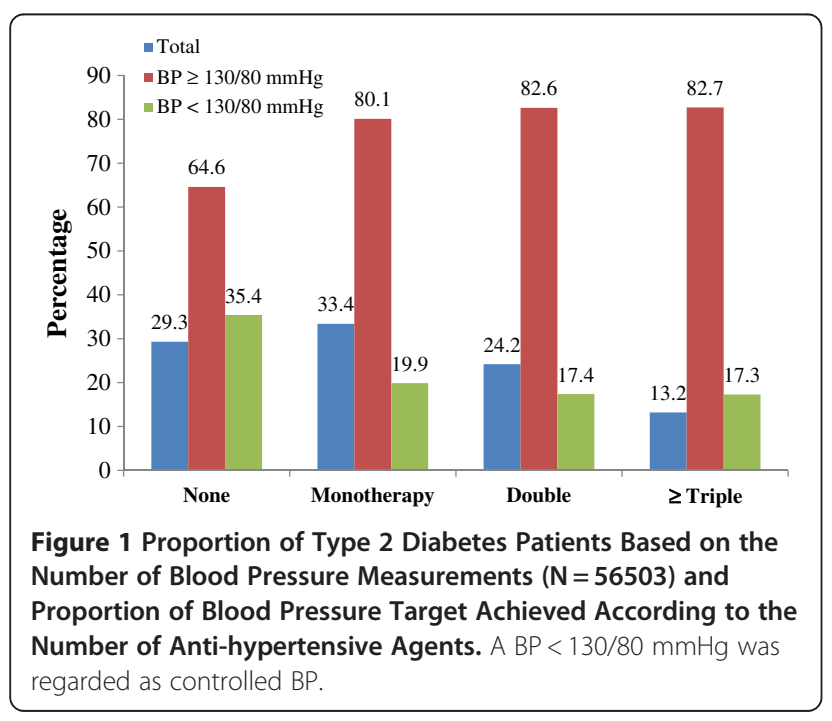

Table 2 Multivariate logistic regression used stepwise method conducted for uncontrolled hypertension, $n=43223$

\begin{tabular}{llll}
\hline Independent variables: & OR & $\mathbf{9 5} \% \mathbf{C l}$ & P value \\
\hline Type of Health Clinic & & & \\
\hline Without FMS/doctor & 1.11 & $1.04,1.18$ & 0.002 \\
\hline With FMS/doctor & 1 & - & - \\
\hline Age (years) & & & \\
\hline$<30$ & 1 & - & - \\
\hline $30-49$ & 1.18 & $0.89,1.56$ & 0.24 \\
\hline $50-69$ & 1.30 & $0.99,1.72$ & 0.06 \\
\hline$\geq 70$ & 1.28 & $0.96,1.71$ & 0.09 \\
\hline Ethnicity & & & \\
\hline Malay & 1.41 & $1.30,1.52$ & $<0.001$ \\
\hline Chinese & 1.19 & $1.09,1.31$ & $<0.001$ \\
\hline Indian & 1 & - & - \\
\hline Duration of diabetes (years) & & & \\
\hline$<5$ & 1.12 & $1.02,1.22$ & 0.01 \\
\hline $5-9$ & 0.96 & $0.87,1.05$ & 0.33 \\
\hline$\geq 10$ & 1 & - & - \\
\hline BMI & & & \\
\hline
\end{tabular}

BMI (kg/m2)

\begin{tabular}{llll}
\hline$<23$ & 1 & - & - \\
\hline$\geq 23$ & 1.35 & $1.26,1.44$ & $<0.001$ \\
\hline
\end{tabular}

Anti-Hypertensive Agent

\begin{tabular}{llll}
\hline On Anti-Hypertensive/s & 1 & - & - \\
\hline No Anti-Hypertensive & 0.37 & $0.34,0.39$ & $<0.001$ \\
\hline Ischaemic Heart Disease & & & \\
\hline Absent & 1 & - & - \\
\hline Present & 0.84 & $0.72,0.97$ & 0.02
\end{tabular}

\section{Nephropathy}

\begin{tabular}{llll}
\hline Absent & 1 & - & - \\
\hline Present & 0.87 & $0.78,0.97$ & 0.01 \\
\hline $\mathbf{L D L}>2.6 \mathrm{mmol} / \mathrm{L}$ & 1.13 & $1.06,1.21$ & $<0.001$ \\
\hline$\leq 2.6 \mathrm{mmol} / \mathrm{L}$ & 1 & - & -
\end{tabular}

$\mathrm{Cl}=$ confidence interval; $\mathrm{OR}=$ odds ratio.

than two antihypertensive agents. Others have had a similar experience [4,19-22].

Our findings suggested that treating BP to target was associated with less proportion of lipid profiles and HbA1c not at treatment targets (20-25\%). It was not the case in reverse when treating these lipid profiles and HbA1c to targets, we noticed that a large proportion of T2D patients were still not at BP target (about $75 \%$ ). Therefore, simultaneous management of all these risk factors is most cost-effective via BP lowering effort. Sever $\mathrm{P}$ et al reported a potential synergy between the use of amlodipine-based blood pressure lowering agent and lipid lowering agent (atorvastatin $10 \mathrm{mg}$ ) in the Anglo-Scandinavian Cardiac Outcomes Trial (ASCOT) which comprised 10305 patients with about a quarter of 
them were with diabetes mellitus [23]. There was a $53 \%$ reduction in the relative risk of coronary heart disease when patients received both these agents compared to using only statins (36\%). Perhaps, as has been confirmed by other studies, such combinations should be started early in our patients in order to achieve maximum benefit $[24,25]$.

Of the demographic characteristics, we found that those who were $>50$ years old, recently diagnosed with diabetes, overweight (and obese) and of Malay ethnicity were more likely to have uncontrolled BP and require closer monitoring. The high proportion of Malays was probably a reflection of the population distribution in Malaysia with Malays being the dominant race. It has been shown that a combination of T2D, resistant hypertension and obesity was related to autonomic imbalance (heart rate variability) and circadian disruption of the sympathetic and parasympathetic tones during day and night periods. These effects may contribute to the observed increased risk of cardiovascular morbidity and mortality [26]. Preventive measures should therefore concentrate on these patients. In our experience, gender was not an independent risk factor for uncontrolled BP. The Western experience was different. In Sweden, female patients with diabetes were found to exhibit more uncontrolled hypertension [27]. The Mayo clinic experience in the USA showed that in their group of 1090 diabetic patients with hypertension, older female, with isolated systolic hypertension and with uncontrolled BP at baseline were predictors of uncontrolled BP $(\geq 130$ / $85 \mathrm{mmHg}$ ) [28]. Our patients who had either nephropathy or IHD had better control of their blood pressures. The experience in MAYO clinic was similar [28]. The most probable reason was that these patients were under the care of specialists and in the hospitals. However, the Swedish experience was different; despite more than $94 \%$ of them being on anti-hypertensives, good control of blood pressure was achieved in only $60 \%$ of these patients [29].

The way in which our patients were being treated with hypertensive agents appears to be less than satisfactory. More than half of the patients were on two or more drugs and despite this; good control has not been achieved. Granted that most patients with T2D diabetes may require combination therapy [30] but the proper combination is important. The combination of a reninangiotensin-aldosterone system (RAAS) inhibitors and a $\mathrm{CCB}$ has been shown to be an effective combination [31,32].

Therefore the education of the physicians managing these patients, the use of proper combinations, attending to the individual needs of the patient and adherence to guidelines are ways in which this area can be improved [33]. Thus, training program in this aspect of prescribing for diabetic hypertensive is ever more needed for the majority non-specialist primary care physicians. Pertinent aspects of drugs prescription should include safety issues such as monitoring of renal function postinitiation of a RAAS inhibitor, not over-aggressive in treating systolic $\mathrm{BP}(<120 \mathrm{mmHg})$ in $\mathrm{T} 2 \mathrm{D}$ patients who are at high risk for CVD events [34]. Patient-centred consultation strategies to enhance patient participation in decision making and to empower patient on hypertension self-management that would improve therapy adherence [35]. Besides, the clinicians should be encouraged out of inertia and taught on adding the third and more anti-hypertensive agents judiciously because some over-weighing the risk of polypharmacy against the optimal BP control [36]. The limited availability of certain anti-hypertensive agents such as the long-acting CCB and ARB could be the underlying cause of the majority patients under non-specialist primary care physician care did not achieve target BP level.

Not surprisingly, BP control among the T2D patients was better at the health clinics where a doctor was present when compared to those without. Rohana D et al has shown convincing evidence that in Malaysia, where the clinics were manned by a $\mathrm{M} \& \mathrm{HO}$ or family physician, the care was significantly better [37]. The solution therefore is to man more clinics with doctors or if that is not possible, have in place a proper and appropriate referral system for those patients whose hypertension prove difficult to control. An alternative is to transfer these patients to a neighbouring general practice clinic but the organization and logistics of doing so can be difficult [38].

There may be other factors that may have contributed to the poor control of hypertension. Concentration on the glycaemic control (HbA1c) at the expense of the hypertension could be one factor [39,40]. Inadequate training for our physicians on the principles of evidence based guidelines and health system that support these guidelines adherence may be another [41-43]. Failure to individualise treatment according to the needs of the patient and the lack of a team approach involving nurses, medical assistants, pharmacists, nutritionists/dietitians may be another factor $[40,44,45]$. Providing guidelines, having appropriate protocols and knowledge instruments that has been validated for use in this country should be put in place and then, perhaps the medical care for diabetic hypertensive would improve $[42,46]$.

The limitations of our study are recognized. The sample studied may not have been representative of the country. Not all hospitals or health clinics were involved in the survey. Furthermore, $20 \%$ of the blood pressure recordings were missing [47]. A large proportion of diabetic patients are being managed in the private sector and the situation with regards to control of blood 
pressure may have been different. Other factors that may affect the results such as the socioeconomic status, health literacy, professional support, mental disorders, smoking, physical activity, alcohol consumption, medication adherence etc. were not considered in our study $[48,49]$. Notwithstanding these deficiencies, we feel that a large sample size of 70,000 patients and from their demographic characteristics may actually be representative of patients with T2D seeking treatment in the Public Health Centres.

\section{Conclusions}

T2D patients who were older, recently diagnosed, obese and having care at a health clinic without a doctor were more likely to have uncontrolled BP. These patients can be clearly identified and therefore preventive measures should concentrate on this group of patients. The inappropriate use of anti-hypertensive agent may be another identifiable reason for the poor control of hypertension. Investment in these areas in terms of appointment of trained physicians to health clinics and drawing up proper guidelines in their management of hypertension, especially in improving physician prescribing capability, should be a priority in order to reduce the unfavourable consequences of hypertension in our patients with T2D.

\section{Abbreviations \\ T2D: Type 2 diabetes; BP: Blood pressure; HDS: Hypertension in Diabetes Study; NNT: Number needed to treat; QALYs: Quality-adjusted life-years; ADCM: Adult Diabetes Control and Management; CRF: Case record form; FMS: Family medicine specialists; ADA: Anti-hyperglycaemic agents; LDL- C: Low density lipoprotein-cholesterol; TG: Triglyceride; HDL-C: High density lipoprotein-cholesterol; CVD: Cerebrovascular disease/stroke; IHD: Ischemic heart disease; ED: Erectile dysfunction; BMI: Body mass index; ACEl: Angiotensin-converting enzyme inhibitors; CCB: Calcium channel blockers.}

\section{Competing interests}

The authors declare that they have no competing interests.

\section{Authors' contributions}

$\mathrm{MI} \& \mathrm{CBH}$ collected data; $\mathrm{CBH}$ drafted the manuscript; $\mathrm{MAB} \& \mathrm{CBH}$, performed statistical analysis. All authors read, edited and approved the final manuscript.

\section{Acknowledgement}

This study received funding from Ministry of Health, Malaysia. We would like to acknowledge the Director General of Health Malaysia for his support in setting up the registry and his permission to publish this report. We are grateful to the following steering committee members of ADCM who had contributed to the success of the registry: Professor Wan Mohamed Wan Bebekar, Dr Zanariah Hussein, Dr G.R. Letchumanan a/k Ramanathan, Dr Rozita Zakariah, Professor Fatimah Harun, Dr Syed Alwi Syed Abd. Rahman and Dr Asmah Zainal Abidin. We would like to thank Noor Akma Hassim and Tee Chin Kim who were at Clinical Research Centre, Kuala Lumpur for all their statistic and logistic support. Special thanks also goes to Ms Lena Yeap from ClinResearch Sdn Bhd for her and team previous statistical support. This study has been approved by the Medical Research Ethics Committee (MREC) on Dec 2008. Protocol Number from the National Medical Research Register: NMRR ID: 08-12-1167.

\section{Author details}

${ }^{1}$ Department of Family Medicine, Faculty of Medicine \& Health Sciences, Universiti Putra Malaysia, 43400 Serdang, Selangor, Malaysia. ${ }^{2}$ Klinik Kesihatan Seremban 2, Negeri Sembilan, Malaysia. ${ }^{3}$ Klinik Kesihatan Bandar Sungai Petani, Kedah, Malaysia. ${ }^{4}$ Clinical Research Centre, Hospital Kuala Lumpur, Kuala Lumpur, Malaysia. ${ }^{5}$ Disease Control Division, Ministry of Health Malaysia, Putrajaya, Malaysia.

Received: 8 February 2012 Accepted: 7 May 2012

Published: 18 May 2012

\section{References}

1. Williams B: The Hypertension in Diabetes Study (HDS): a catalyst for change. Diabet Med 2008, 25(Suppl 2):13-19.

2. Joffres MR, Hamet P, MacLean DR, L'Italien GJ, Fodor G: Distribution of blood pressure and hypertension in Canada and the United States. Am J Hypertens 2001, 14(11 Pt 1):1099-1105.

3. Hypertension in Diabetes Study G: HDS 1: Prevalence of hypertension in newly presenting type 2 diabetic patients and the association with risk factors for cardiovascular and diabetic complications. J Hypertens 1993, 11(3):309-317.

4. McLean DL, Simpson SH, McAlister FA, Tsuyuki RT: Treatment and blood pressure control in 47,964 people with diabetes and hypertension: $\mathrm{A}$ systematic review of observational studies. Can J Cardiol 2006, 22(10):855-860.

5. Chen G, McAlister FA, Walker RL, Hemmelgarn BR, Campbell NRC: Cardiovascular Outcomes in Framingham Participants With Diabetes: The Importance of Blood Pressure. Hypertension 2011, 57(5):891-897.

6. Williams B: Hypertension in Diabetes. London and New York: Martin Dunitz Publisher; 2003:99-108

7. Nosadini R: Blood glucose in relation to blood pressure control as risk factors in the progression of renal damage in type 2 diabetes. International Congress Series 2003, 1253:295-299.

8. Fowler MJ: Microvascular and Macrovascular Complications of Diabetes. Clin Diabetes 2008, 26(2):77-82.

9. Adler Al, Stratton IM, Neil HAW, Yudkin JS, Matthews DR, Cull CA, Wright AD, Turner RC, Holman RR: Association of systolic blood pressure with macrovascular and microvascular complications of type 2 diabetes (UKPDS 36): prospective observational study. BMJ 2000, 321(7258):412419.

10. Raikou M, Gray A, Briggs A, Stevens R, Cull C: Cost effectiveness analysis of improved blood pressure control in hypertensive patients with type 2 diabetes: UKPDS 40. UK Prospective Diabetes Study Group. BMJ 1998, 317(7160):720-726.

11. Clarke P, Gray A, Briggs A, Stevens R, Matthews D, Holman R: Cost-utility analyses of intensive blood glucose and tight blood pressure control in type 2 diabetes (UKPDS 72). Diabetologia 2005, 48(5):868-877.

12. Ibrahim WN, Aljunid S, Ismail A: Cost of Type 2 Diabetes Mellitus in Selected Developing Countries. Malaysian Journal of Public Health Medicine 2010, 10(2):68-71.

13. Ismail Mastura, Chew BH, Lee PY, Cheong AT, Sazlina SG, Jamaiyah H, Alwi SARS, Wahyu TS, Zaiton A: Control and Treatment Profiles of 70,889 Adult Type 2 Diabetes Mellitus Patients in Malaysia. International Journal of Collaborative Research on Internal Medicine \& Public Health 2011, 3(1):98-113.

14. Awin N: A Review of Primary Health Care in Malaysia- A Report for the World Health Organization Western Pacific Region. Malaysia: Ministry of Health; 2000:6-23.

15. Noor Ghani S, Yadav H: Health Care in Malaysia. Kuala Lumpur: University of Malaya Press; 2008

16. Ministry Of Health: MOH Drug Formulary, vol. 3/2011. Malaysia: Putrajaya: Ministry of Health; 2011.

17. Ministry of Health Malaysia: Management of Type 2 Diabetes Mellitus. Putrajaya: Technology, Health Section, Assessment Division, Medical Development; 2009.

18. American Diabetes Association: Treatment of Hypertension in Adults With Diabetes. Diabetes Care 2003, 26(suppl 1):s80-s82.

19. Eliasson B, Cederholm J, Nilsson P, Gudbjörnsdóttir S, for the Steering Committee of the Swedish National Diabetes R: The gap between guidelines and reality: Type 2 diabetes in a national diabetes register 1996-2003. Diabet Med 2005, 22(10):1420-1426. 
20. Sazlina SG, Zaiton A, Ong I: A Clinical Audit on Diabetes Care in Two Urban Public Primary Care Clinics in Malaysia. Malaysian Journal of Medicine and Health Sciences 2010, 6(1):101-109.

21. Sabanayagam C, Shankar A, Saw SM, Tai ES, Lim SC, Lee JJ-M, Wong TY: Prevalence of Diabetes Mellitus, Glycemic Control, and Associated Factors in a Malay Population in Singapore. Asia Pac J Public Health 2009, 21(4):385-398.

22. Howteerakul N, Suwannapong N, Rittichu C, Rawdaree P: Adherence to Regimens and Glycemic Control of Patients with Type 2 Diabetes Attending a Tertiary Hospital Clinic. Asia Pac J Public Health 2007, 19(1):43-49.

23. Sever P, Dahlöf B, Poulter N, Wedel H, Beevers G, Caulfield M, Collins R, Kjeldsen S, Kristinsson A, McInnes G, et al: Potential synergy between lipidlowering and blood-pressure-lowering in the Anglo-Scandinavian Cardiac Outcomes Trial. Eur Heart J 2006, 27(24):2982-2988.

24. Jackson R, Lawes CMM, Bennett DA, Milne RJ, Rodgers A: Treatment with drugs to lower blood pressure and blood cholesterol based on an individual's absolute cardiovascular risk. Lancet 2005, 365(9457):434-441.

25. Buse JB, Ginsberg HN, Bakris GL, Clark NG, Costa F, Eckel R, Fonseca V, Gerstein HC, Grundy S, Nesto RW, et al: Primary Prevention of Cardiovascular Diseases in People With Diabetes Mellitus. Diabetes Care 2007, 30(1):162-172.

26. Boer-Martins L, Figueiredo V, Demacq C, Martins L, Consolin-Colombo F, Fiqueiredo M, Cannavan F, Moreno H: Relationship of autonomic imbalance and circadian disruption with obesity and type 2 diabetes in resistant hypertensive patients. Cardiovasc Diabetol 2011, 10(1):24.

27. Leosdottir M, Willenheimer R, Persson M, Nilsson P: The association between glucometabolic disturbances, traditional cardiovascular risk factors and self-rated health by age and gender: A cross-sectional analysis within the Malmo Preventive Project. Cardiovasc Diabeto/ 2011, 10(1):118.

28. Duggirala MK, Cuddihy RM, Cuddihy M-T, Naessens JM, Cha SS, Mandrekar JN, Leibson CL: Predictors of Blood Pressure Control in Patients With Diabetes and Hypertension Seen in Primary Care Clinics. Am J Hypertens 2005, 18(6):833-838.

29. Gudbjörnsdottir S, Eeg-Olofsson K, Cederholm J, Zethelius B, Eliasson B, Nilsson PM, on behalf of the Swedish National Diabetes R: Risk factor control in patients with Type 2 diabetes and coronary heart disease: findings from the Swedish National Diabetes Register (NDR). Diabet Med 2009, 26(1):53-60.

30. Konzem SL, Devore VS, Bauer DW: Controlling hypertension in patients with diabetes. Am Fam Physician 2002, 66(7):1209-1214.

31. Neldam S, Lang M, Jones $R$, On behalf of the T-l: Telmisartan and Amlodipine Single-Pill Combinations vs Amlodipine Monotherapy for Superior Blood Pressure Lowering and Improved Tolerability in Patients With Uncontrolled Hypertension: Results of the TEAMSTA-5 Study. J Clin Hypertens 2011, 13(7):459-466.

32. Dahlöf B, Sever PS, Poulter NR, Wedel H, Beevers DG, Caulfield M, Collins R, Kjeldsen SE, Kristinsson A, Mclnnes GT, et al: Prevention of cardiovascular events with an antihypertensive regimen of amlodipine adding perindopril as required versus atenolol adding bendroflumethiazide as required, in the Anglo-Scandinavian Cardiac Outcomes Trial-Blood Pressure Lowering Arm (ASCOT-BPLA): a multicentre randomised controlled trial. Lancet 2005, 366(9489):895-906.

33. Abdulameer SA, Sahib MN, Aziz NA, Hassan Y, Alrazzaq HA, Ismail O: Physician adherence to hypertension treatment guidelines and drug acquisition costs of antihypertensive drugs at the cardiac clinic: a pilot study. Patient Prefer Adherence 2012, 6:101-108.

34. Effects of Intensive Blood-Pressure Control in Type 2 Diabetes Mellitus. $N$ Engl J Med 2010, 362(17):1575-1585.

35. Tan MY, Magarey JM, Chee SS, Lee LF, Tan MH: A brief structured education programme enhances self-care practices and improves glycaemic control in Malaysians with poorly controlled diabetes. Health Educ Res 2011, 26(5):896-907.

36. Grant RW, Cagliero E, Dubey AK, Gildesgame C, Chueh HC, Barry MJ, Singer DE, Nathan DM, Meigs JB: Clinical inertia in the management of Type 2 diabetes metabolic risk factors. Diabet Med 2004, 21(2):150-155.

37. Rohana D, Wan Norlida WI, Nor Azwany Y, Mazlan A, Zawiya D, Che Kamaludin CA, Cs CG: Economic Evaluation of Type 2 Diabetes Management at the Malaysian Ministry of Health Primary Care Clinics, in Machang, Kelantan. Malaysian Journal of Public Health Medicine 2007, 7(1):5-13.
38. National Healthcare Establishments \& Workforce Statistics (Primary Care) 2008-2009. Kuala Lumpur: Clinical Research Centre, Ministry of Health, Malaysia; 2011.

39. Elasy T: Improving Diabetes Outcomes: Beyond Glucocentricity. Clin Diabetes 2008, 26(1):1-2.

40. Putnam W, Lawson B, Buhariwalla F, Goodfellow M, Goodine R, Hall J, Lacey K, MacDonald I, Burge F, Natarajan N, et al: Hypertension and type 2 diabetes: What family physicians can do to improve control of blood pressure - an observational study. BMC Fam Pract 2011, 12(1):86.

41. Chan GC, Teng CL: Primary care doctors' perceptions towards evidencebased medicine in Melaka State: a questionnaire study. Med J Malaysia 2005, 60(2):130-133.

42. Kaissi AA, Parchman M: Organizational Factors Associated With Selfmanagement Behaviors in Diabetes Primary Care Clinics. Diabetes Educ 2009, 35(5):843-850.

43. Holbrook A, Thabane L, Keshavjee K, Dolovich L, Bernstein B, Chan D, Troyan S, Foster G, Gerstein H, for the CIII: Individualized electronic decision support and reminders to improve diabetes care in the community: COMPETE II randomized trial. CMAJ 2009, 181(1-2):37-44.

44. Simpson SH, Majumdar SR, Tsuyuki RT, Lewanczuk RZ, Spooner R, Johnson JA: Effect of Adding Pharmacists to Primary Care Teams on Blood Pressure Control in Patients With Type 2 Diabetes. Diabetes Care 2011, 34(1):20-26.

45. Simkin-Silverman LR, Conroy MB, Bhargava T, McTigue KM: Development of an Online Diabetes Prevention Lifestyle Intervention Coaching Protocol for Use in Primary Care Practice. Diabetes Educ 2011, 37(2):263-268.

46. Lai P, Chua SS, Tan CH, Chan SP: Validation of the Diabetes, Hypertension and Hyperlipidemia (DHL) knowledge instrument in Malaysia. BMC Med Res Methodol 2012, 12(1):18.

47. BoonHow C, Theng CA, Ismail M, Rahman SASA: Diabetic Hypertensive Control And Treatment: A Descriptive Report From The Audit Diabetes Control And Management (ADCM) Registry. Malaysian Family Physician 2010, 5(3):134-138

48. Larrañaga I, Arteagoitia JM, Rodriguez JL, Gonzalez F, Esnaola S, Piniés JA the Sentinel Practice Network of the Basque C: Socio-economic inequalities in the prevalence of Type 2 diabetes, cardiovascular risk factors and chronic diabetic complications in the Basque Country, Spain. Diabet Med 2005, 22(8):1047-1053.

49. Gallo JJ, Bogner HR, Morales KH, Post EP, Ten Have T, Bruce ML: Depression, cardiovascular disease, diabetes, and two-year mortality among older, primary-care patients. Am J Geriatr Psychiatry 2005, 13(9):748-755.

\section{doi:10.1186/1475-2840-11-54}

Cite this article as: Chew et al:: Determinants of uncontrolled

hypertension in adult type 2 diabetes mellitus: an analysis of the Malaysian diabetes registry 2009. Cardiovascular Diabetology 2012 11:54

\section{Submit your next manuscript to BioMed Central and take full advantage of:}

- Convenient online submission

- Thorough peer review

- No space constraints or color figure charges

- Immediate publication on acceptance

- Inclusion in PubMed, CAS, Scopus and Google Scholar

- Research which is freely available for redistribution 